\title{
Using evidential reasoning approach for prioritization of maintenance-related waste caused by human factors- a case study
}

\author{
Farzaneh Ahmadzadeh $^{1} \cdot$ Marcus Bengtsson $^{2}$
}

Received: 22 April 2016/Accepted: 22 August 2016/Published online: 21 October 2016

(C) The Author(s) 2016. This article is published with open access at Springerlink.com

\begin{abstract}
The reduction and elimination of maintenancerelated waste is receiving increasing attention because of the negative effect of such waste on production costs. The overall goal of this research is to identify and prioritize factors that can be considered maintenance-related waste within the automotive manufacturing industry. Five manufacturing companies participated in a workshop to identify root causes of maintenance-related waste; 16 categories were found. The identified factors were heavily reliant on human factors as a root or major contributory cause at different levels affecting performance and productivity. For prioritization, the evidential reasoning (ER) approach which is one of the latest developments in multi-criteria decision-making is applied. A basic tree structure necessary for ER assessment is developed based on the workshop results as well as literature on human factors. Then, a survey on basic attributes at the lowest level of this tree is designed and performed at one of the companies participating in the workshop. The application of ER shows that, on an overall level, "management condition" is in first order and "maintainer condition" and "working condition" are in second and third order respectively as the worst cases for creating maintenance-related waste. On the most delimited level "inadequate resources" and "weather/indoor climate"
\end{abstract}

Farzaneh Ahmadzadeh

farzaneh.ahmadzadeh@mdh.se

Marcus Bengtsson

marcus.bengtsson@mdh.se

1 Mälardalen University, School of Innovation, Design and Engineering, Eskilstuna, Sweden

2 Volvo Construction Equipment Operations and Mälardalen University, School of Innovation, Design and Engineering, Eskilstuna, Sweden have the highest and lowest average scores respectively in ER ranking or prioritization. This methodology with its resulting ranking can be used as a tool to create awareness for managers seeking to reduce or eliminate maintenancerelated waste.

Keywords Multiple criteria analysis - Maintenance . Human factors · Evidential reasoning · Prioritization

\section{Introduction}

The reduction and elimination of maintenance-related waste is attracting critical attention because of its importance for successful operations. As early as in the 1990s, it was estimated that one third of maintenance costs were unnecessary and basically waste [1]. "Waste" can be defined as "everything that increases cost without adding value to the customer" [2]. Since today's production systems are often guided by complex production strategies and modern automated activities to meet customer demand and to compete in a global economy, it is increasingly important for maintenance functions to decrease their negative effects on production capacity and to do so without affecting the budget.

Advanced technology has obviously increased the complexity of tasks and time in the maintenance field; this, in turn, has significantly increased the human impact and is considered as root cause of many accidents [3]. Here, "maintenance" is defined as those activities required to keep a facility in asbuilt condition and continuing to have its original productive capacity, and "human error" is defined as the failure to perform a specified task or the performance of a forbidden action that could lead to disruption of scheduled operations or result in damage to property and equipment [4]. Since humans play an important role in design, installation, production, and 
maintenance [5] in every industry, including manufacturing, quality of maintenance is heavily reliant on human activities because many accidents have maintainer error as a root or a major contributory cause of problems in performance and productivity. Literature on maintenance-related waste exists but tends to lean on the original seven wastes [6]: overproduction, waiting, inventory, motion, defects, over-processing, and transportation. Several researchers have translated the seven wastes into a maintenance context. Davis and Greenough [7] note the original seven wastes; Bicheno et al. [8] add seven more; Baluch et al. [9] discuss eight wastes, closely connected to the seven original ones. But none tackle the root causes of the waste which, in many instances, is related to human error. Therefore, the focus of this study is to identify and then to prioritize maintenance-related waste created by human factors in automotive manufacturing industry. The most important identified factors could be used by maintenance management teams to increase awareness about the most important human factors behind maintenance-related wastes to take alternative actions to reduce or eliminate them.

The rest of the paper is organized as follows. Section 2 briefly outlines the evidential reasoning (ER) approach and how it works as prioritization method. Section 3 explains the process of collecting evidence using maintenance repair persons and engineers to identify the wastes and provision of hierarchy model. Section 4 provides data analysis and a discussion, while Section 5 offers a conclusion.

\section{Method: introduction to ER approach}

To a large extent, decision-making takes place in an environment in which the goals, constraints, and consequences of possible actions are not known precisely. This means prioritization of a range of alternatives and selecting the optimal one is a hard task in real-world complex problems. The qualitative nature of the decision criteria's and information uncertainties like incomplete, missing or imprecise data make the ranking process even more difficult in multi-criteria decision-making (MCDM) [10]. Many MCDM methods have been developed, such as multiple attribute utility theory (MAUT) and analytical hierarchy process (AHP) [11-15]. Most of these methods are suitable for solving small scale MCDM problems without uncertainty. In uncertain situations, the fuzzy multi-criteria decision-making (FMCDM) approach provides an ideal option; it has been tested by a number of researchers to rank alternatives in different situations [16-24]. However, the fuzzy approach is used only when uncertainty is predominant. In other words, when a particular parameter is quantifiable with fair degree of accuracy, or there are a missing or incomplete data this approach need not be used. Most real-life decisions use a mixture of qualitative and quantitative attributes with varying degrees of uncertainties, increasing the need for the development of scientific methods and tools that are rational, reliable, repeatable, and transparent.

Evidential reasoning (ER) advocates a general, multi-level evaluation process for dealing with MCDM problems. The process can model various types of qualitative and quantitative uncertainties and is developed on the basis of DempsterShafer evidence theory [25] and evaluation analysis model [26] and decision theory. With the introduction of the concepts of belief structure [26-28] and the belief decision matrix [29], it became possible to model various types of uncertainties in a unified format [30]. The outcomes of the ER algorithm include not only average performance scores of alternatives on each criterion but also the distributions of their performance variations which reveal the strengths and weaknesses of each option. When there are uncertainties in the input data, the ER algorithm can calculate the lower and upper bound of the score ranges of alternatives. Such score ranges show the combined effects of uncertainties in different parameters to the rankings of different options [29]. In recent years, several authors have investigated the application of ER for MCDM problems under uncertainty [28, 31-35] and a significant amount of work has emerged in literature, e.g., motorcycle assessment [26], general cargo ship design [36], software safety synthesis [37], organizational self-assessment [38], risk evaluation [39], location problems [40] and [41], discounting techniques in aerospace design [42], expert systems [43], new product development $[44,45]$, supplier prioritization [46], decision-making [30, 47], and decision support [48].

\subsection{Basic evaluation framework}

The evidential reasoning algorithm can be used on MCDM problems, where a complex general property which is usually difficult to assess directly is broken down and operationalized by using well-defined, measurable concepts that together constitute the general property. The result of such a breakdown is a multiple attribute framework taking the shape of a tree (hierarchy) structure, with assessable basic attributes at the lowest level. The assessment of these basic attributes can be aggregated to an assessment of the upper level of the tree, see Fig. 1. Upon assessment of the basic attributes, however, there is always a certain level of uncertainty. The Dempster-Shafer mathematics is designed to aggregate the uncertainties in the basic attributes to a total uncertainty of the total assessment.

\subsection{ER approach based on Dempster-Shafer theory}

Steps for the overall assessment of the complex general property are suggested by Yang [34] based on DempsterShafer theory [25] and summarized by Pontus et al. [49] are as following. The application of Dempster-Shafer 


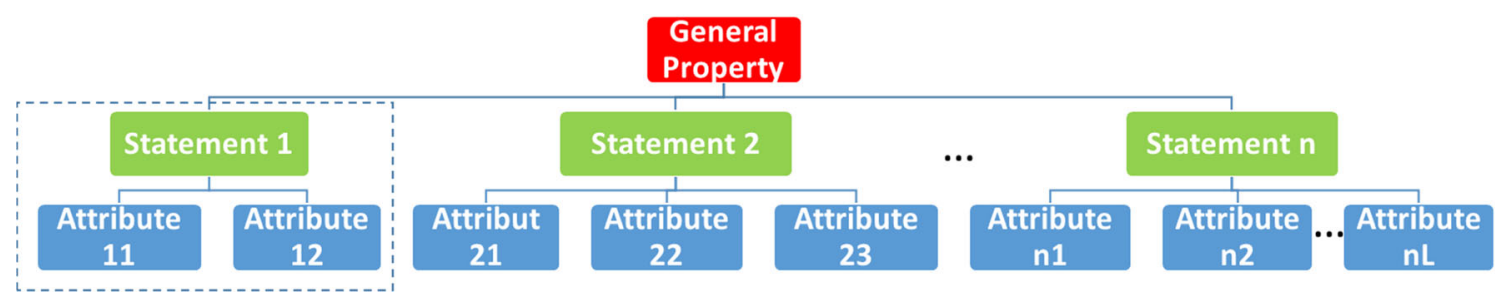

Fig. 1 A generic framework for assessment of general property

theory described on one sub tree (dashed rectangular in Fig. 1) and reasoning can be generalized to an entire tree consisting of several sub trees.

Step 1. Define a set of $L$ basic attributes include all the factors influencing the assessment of the upper level attribute as:

$$
E=\{\varepsilon 1, \varepsilon 2, \ldots, \varepsilon L\}
$$

Now estimate the relative weights of the attributes where $\omega_{i}$ is the relative weight for basic attribute $\varepsilon_{i}$ and is normalized so that $\sum \omega_{i=1}$ and $0 \leq \omega_{i} \leq 1$. Moreover, define $N$ distinctive evaluation grades $H_{n}, n=1, \ldots, N$ as a complete set of standards to assess each option on all attributes. For example:

$H=\left\{H_{1}=\right.$ worst,$H_{2}=$ poor,..,$H_{N-1}=$ good, $H_{N}=$ Excellent $\}$

For each attribute $\varepsilon_{i}$ and evaluation grade $H_{n}$ a degree of belief $\beta_{n}$ is assigned. The degree of belief denotes the source's level of confidence when assessing the level of fulfillment of a certain property.

Step 2. Let $m_{n, i}$ be a basic probability mass, representing the degree to which the $i^{\text {th }}$ basic attribute $\varepsilon_{i}$ supports a hypothesis that the general attribute is assessed to the $n^{\text {th }}$ evaluation grade $H_{n}$. Then, $m_{n, i}$ is calculated as follows:

$$
m_{\mathrm{n}, \mathrm{i}}=\omega_{\mathrm{i}} \beta_{\mathrm{n}, 1}
$$

Let $\mathrm{m}_{\mathrm{H}, \mathrm{i}}$ be the remaining probability mass unassigned to each basic attribute $\varepsilon_{i}$, so $m_{H, i}$ is calculated as follows:

$m_{H, i}=1-\sum_{n=1}^{N} m_{n, i}=1-\omega i \sum_{n=1}^{N} \beta_{n, i}$

Decompose $m_{H, i}$ into $\bar{m}_{H, \mathrm{i}}$ and $\tilde{m}_{H, \mathrm{i}}$ as follows:

$$
\begin{aligned}
& \bar{m}_{H, \mathrm{i}}=1-\omega_{\mathrm{i}} \text { and } \tilde{m}_{H, \mathrm{i}}=\omega_{\mathrm{i}}\left(1-\sum_{n=1}^{N} \beta_{n, \mathrm{i}}\right) \\
& m_{H, \mathrm{i}}=\bar{m}_{H, \mathrm{i}}+\tilde{m}_{H, \mathrm{i}}
\end{aligned}
$$

Step 3. The assessments of the basic attributes constituting the general property are aggregated to form a single assessment of the general property. The probability masses assigned to the various assessment grades, as well as the probability mass left unassigned, are denoted by $m_{\mathrm{n}, \mathrm{I}(\mathrm{L})}, \bar{m}_{\mathrm{H}, \mathrm{I}(\mathrm{L}),}, \tilde{m}_{\mathrm{H}, \mathrm{I}(\mathrm{L})}$ and $m_{\mathrm{H}, \mathrm{I}(\mathrm{L})}$. Let $I(1)=1$.
This gives us $m_{n, I(I)}=m_{n, 1}(n=1, \ldots, N)$, $\bar{m}_{H, I(1)}=\bar{m}_{H, 1}, \tilde{m}_{H, I(1)}=\tilde{m}_{H, 1}$ and $m_{H, I(1)=} m_{H, I}$. The combined probability masses can be generated by aggregating all the basic probability assignments using the following recursive ER algorithms:

$$
\begin{array}{r}
\left\{H_{n}\right\}: m_{\mathrm{n},(\mathrm{i}+1)}=\mathrm{K}_{\mathrm{I}(\mathrm{i}+1)}\left[\begin{array}{l}
m_{\mathrm{n},(\mathrm{i})} \times m_{\mathrm{n}, \mathrm{i}+1}+m_{\mathrm{H}, \mathrm{I}(\mathrm{i})} \\
\times m_{\mathrm{n}, \mathrm{i}+1}+m_{\mathrm{n}, \mathrm{I}(\mathrm{i})} \times m_{\mathrm{H}, \mathrm{i}+1}
\end{array}\right] \\
n=\{1,2, \ldots, N\}
\end{array}
$$

In Eq. (5), we continue to let $i=1$. The term $m_{n, 1}, m_{n, 2}$ measures the degree of attributes $\varepsilon_{1}$ and $\varepsilon_{2}$ supporting the general attribute $y$ to be assessed to $H n$, the term $m_{n, 1}, m_{H, 2}$ measures the degree of only $\varepsilon_{1}$ supporting $y$ to be assessed to $H_{n}$, and the term $m_{H, 1}, m_{n, 2}$ measures the degree of only $\varepsilon_{2}$ supporting $y$ to be assessed to $H_{n}$.

$$
\{H\}: m_{\mathrm{H}, \mathrm{I}(\mathrm{i})}=\bar{m}_{\mathrm{H}, \mathrm{I}(\mathrm{i})}+\tilde{m}_{\mathrm{H}, \mathrm{I}(\mathrm{i})}
$$

$\tilde{m}_{\mathrm{H}, \mathrm{I}(\mathrm{i}+1)}=\mathrm{K}_{\mathrm{I}(\mathrm{i}+1)}\left[\begin{array}{l}\tilde{m}_{\mathrm{H}, \mathrm{I}(\mathrm{i})} \times \tilde{m}_{\mathrm{H}, \mathrm{i}+1}+\bar{m}_{\mathrm{H}, \mathrm{I}(\mathrm{i})} \\ \times \tilde{m}_{\mathrm{H}, \mathrm{i}+1}+\tilde{m}_{\mathrm{H}, \mathrm{I}(\mathrm{i})} \times \bar{m}_{\mathrm{H}, \mathrm{i}+1}\end{array}\right]$

$\bar{m}_{\mathrm{H}, \mathrm{I}(\mathrm{i}+1)}=\mathrm{K}_{\mathrm{I}(\mathrm{i}+1)}\left[\bar{m}_{\mathrm{H}, \mathrm{I}(\mathrm{i})} \times \bar{m}_{\mathrm{H}, \mathrm{i}+1}\right]$

$$
\begin{aligned}
K_{I(i+1)}= & {\left[1-\sum_{t=1}^{N} \sum_{j=1}^{N} m_{t, I(i)} \cdot m_{j, i+1}\right]^{-1} } \\
& i=\{1,2, \ldots, L-1\}
\end{aligned}
$$

In Eq. (7), the term $\tilde{m}_{\mathrm{H}, 1}, \tilde{m}_{\mathrm{H}, 2}$ measures the degree to which $y$ cannot be assessed to any individual grades due to the incomplete assessments for both $\varepsilon_{1}$ and $\varepsilon_{2}$. The term $\bar{m}_{\mathrm{H}, 1}$, $\tilde{m}_{\mathrm{H}, 2}$ measures the degree to which $y$ cannot be assessed due to incomplete assessments for $\varepsilon_{2}$ only. The term $\tilde{m}_{\mathrm{H}, 1}, \bar{m}_{\mathrm{H}, 2}$ measures the degree to which $y$ cannot be assessed due to incomplete assessments for $\varepsilon_{1}$ only. The term $\bar{m}_{\mathrm{H}, 1}, \bar{m}_{\mathrm{H}, 2}$ in Eq. (8) measures the degree to which $y$ has not yet been assessed to individual grades due to the relative importance of $\varepsilon_{1}$ and $\varepsilon_{2}$ 
after $\varepsilon_{1}$ and $\varepsilon_{2}$ have been aggregated. $K_{\mathrm{I}(2)}$ as calculated by Eq. (9) is used to normalize $m_{\mathrm{n}, \mathrm{I}(2)}$ and $m_{\mathrm{H}, \mathrm{I}(2)}$ so that:

$$
\sum_{n=1}^{N} m_{n, I(2)}+m_{H, I(2)}=1
$$

Step 4. Calculating the combined degrees of belief for a higher level property. Let $\beta_{n}$ denote the combined degree of belief that the higher level property assessed to the grade $H_{n}$, generated by combining the assessments for all the associated basic attributes $\varepsilon_{i}$. $\beta_{n}$ is then calculated by:

$$
\begin{gathered}
\left\{H_{n}\right\}: \beta n=\frac{m_{n, I(L)}}{1-\bar{m}_{H, I(L)}} \\
n=\{1,2, \ldots, N\} \\
\{H\}: \beta n=\frac{\tilde{m}_{H, I(L)}}{1-\bar{m}_{H, I(L)}}
\end{gathered}
$$

Steps $1-4$ can now be employed for the other sub-trees, to obtain combined degree of belief for the higher level of the hierarchy model.

Step 5. In this step, the utilities of the respective assessment grades $H_{1 \ldots \mathrm{n}}$ are estimated via utility functions $\left(u\left(H_{n}\right)\right)$. This estimation can be accomplished for instance by means of a range of methods and techniques that can be utilized for this purpose. In this paper however we will not dwell on the subject of utility estimations, rather we assume that the utilities of the respective assessments grade can be appreciated in a linear fashion. Therefore, top level score of the hierarchy model can be obtained by $\sum \beta n u(H n), \mathrm{n}=1 \ldots \mathrm{N}$.

\subsubsection{Illustrative example}

The application of ER approach is described through an example in which a complex property has been broken down to two sub tree but we will focus to the left sub tree (dashed rectangular) in Fig. 1.

Step 1. It is assumed $\omega 1=0.35, \omega 2=0.65, H=\{H 1=$ poor, $H 2=$ average, $H 3=\operatorname{good}\}$. Attribute1 1 is $\varepsilon 1$, is assessed to be poor by an observer, with a degree of belief $\beta 1,1$ of $40 \%$, average $\beta 2,1$ by $50 \%$, and good to the degree of belief $\beta 3,1$ of $0 \%$. It can be presented by the following distribution:

Observer assessment for:
In the same way Attribute 12 which is considered as $\varepsilon_{2}$ can be presented by the following distribution:

Observer assessment for:

$\varepsilon_{2}=\{($ poor $, \beta 1,2=10 \%),($ average $, \beta 2,2=75 \%),(\operatorname{good}, \beta 3,2=15 \%)\}$

Step 2. The probability mass $\mathrm{m}_{1,1}$ for $\varepsilon_{1}$ for different grade values such as poor $\left(H_{1}\right)$ with the values of the weight $\omega_{1}=0.35$ and the degree of belief $\beta_{1,1}$ assigned in step 1 is calculated by applying equation (1) as:

$$
m_{1,1}=\omega_{1} \quad \beta_{1,1}=0.35 \times 0.40=0.14
$$

The probability mass of $\varepsilon_{1}$ being average $\left(H_{2}\right) m_{2,1}$ is:

$m_{2,1}=\omega_{1} \quad \beta_{2,1}=0.35 \times 0.50=0.175$

The probability mass of $\varepsilon_{1}$ being $\operatorname{good}\left(H_{3}\right) m_{3,1}$ is:

$m_{3,1}=\omega_{1} \quad \beta_{3,1}=0.35 \times 0=0$

In a similar way, we calculate the probability mass of $\varepsilon_{2}$ using the values of the weight $\omega_{2}=0.65$ and the assigned degree of belief in step 2 .

$m_{1,2}=\omega_{2} \quad \beta_{1,2}=0.65 \times 0.10=0.065$

The probability mass of $\varepsilon_{2}$ being average $\left(H_{2}\right) m_{2,2}$ is:

$m_{2,2}=\omega_{2} \quad \beta_{2,2}=0.65 \times 0.75=0.4875$

The probability mass of $\varepsilon_{2}$ being $\operatorname{good}\left(H_{3}\right) m_{3,2}$ is:

$m_{3,2}=\omega_{2} \quad \beta_{3,2}=0.65 \times 0.15=0.0975$

The remaining probability mass of $\varepsilon_{1}, \varepsilon_{2}$ obtained by applying equation $(2,3,4)$ and result are shown in Table 1.

$$
\begin{aligned}
& \overline{\mathrm{m}}_{\mathrm{H}, \mathrm{i}}=\quad 1-1-\omega \mathrm{i} \\
& \overline{\mathrm{m}}_{1,1}=1-\omega_{1}=1-0.35=0.65 \\
& \overline{\mathrm{m}}_{1,2}=1-\omega_{2}=1-0.65=0.35 \\
& \tilde{\mathrm{m}}:_{\mathrm{H}, \mathrm{i}}=\omega \mathrm{i}\left(1-\Sigma_{\mathrm{n}=1}^{\mathrm{N}} \beta n, \mathrm{i}\right) \\
& \tilde{\mathrm{m}}:_{1,1}=\omega_{1}\left(1-\Sigma_{\mathrm{n}=1}^{\mathrm{N}} \beta n, \mathrm{i}\right)=0.35(1-0.4-0.5-0)=0.035 \\
& \tilde{\mathrm{m}}_{1,2}=\omega_{2}\left(1-\Sigma_{\mathrm{n}=1}^{\mathrm{N}} 2\right)=0.65(1-0.1-0.75-0.15)=0 \\
& \mathrm{~m}_{\mathrm{H}, \mathrm{i}}=\overline{\mathrm{m}}_{\mathrm{H}, \mathrm{i}}+\tilde{\mathrm{m}}_{\mathrm{H}, \mathrm{i}} \\
& \mathrm{m}_{\mathrm{H}, 1}=\overline{\mathrm{m}}_{\mathrm{H}, \mathrm{i}}+\tilde{\mathrm{m}}_{\mathrm{H}, \mathrm{i}}=0.65+0.035=0.685
\end{aligned}
$$

Step 3. We are now using the recursive ER algorithm to aggregate the probability masses of the basic attributes $\varepsilon_{1}$ and $\varepsilon_{2}$ to the intermediate property 
Table 1 Assigned weights, belief degrees and calculated probability masses

\begin{tabular}{lllllllllllll}
\hline $\begin{array}{l}\text { Evaluation } \\
\text { grade }\end{array}$ & Weight & \multicolumn{1}{l}{ Belief } & \multicolumn{11}{c}{ Probability mass } \\
\hline$H_{1}, H_{2}, H_{3}$ & $\omega_{i}$ & $\beta_{1, i}$ & $\beta_{2, i}$ & $\beta_{3, i}$ & $\beta_{H}$ & $m_{1, i}$ & $m_{2, i}$ & $m_{3, i}$ & $m_{H, i}$ & $\bar{m}_{H, i}$ & $\widetilde{m}_{H, i}$ \\
$\varepsilon_{1}$ & 0.35 & 0.4 & 0.5 & 0 & 0.1 & 0.14 & 0.175 & 0 & 0.685 & 0.65 & 0.035 \\
$\varepsilon_{2}$ & 0.65 & 0.1 & 0.75 & 0.15 & 0 & 0.065 & 0.4875 & 0.0975 & 0.35 & 0.35 & 0 \\
\hline
\end{tabular}

Statement1. Putting the values from Step 2 into equations (5-9) above, gives us an assessment of the Statement 1 property for the grade $H_{1}=$ poor:

From step 2, following are calculated:

$m_{1,1}=0.14, m_{2,1}=0.175, m_{3,1}=0$.

$m_{1,2}=0.065, m_{2,2}=0.4875, m_{3,2}=0.0975$.

and unassigned probability masses are:

$\mathrm{m}_{\mathrm{H}, 1}=0.685, \overline{\mathrm{m}}_{\mathrm{H}, 1}=0.65, \tilde{\mathrm{m}}_{\mathrm{H}, 1}=0.035$.

$\mathrm{m}_{\mathrm{H}, 2}=0.35, \overline{\mathrm{m}}_{\mathrm{H}, 2}=0.35, \tilde{\mathrm{m}}_{\mathrm{H}, 2}=0$.

Therefore:

$$
\begin{aligned}
\mathrm{K}_{\mathrm{I}(2)} & =\left[1-\sum_{t=1}^{3} \sum_{j=1, j \neq t}^{3} m_{\mathrm{t}, \mathrm{I}(\mathrm{i})} \times \mathrm{m}_{\mathrm{j}, \mathrm{i}+1}\right]^{-1} \\
& =\left[\begin{array}{l}
1-\left(m_{1,1} \times m_{2,2}+m_{1,1} \times m_{3,2}\right) \\
+\left(m_{2,1} \times m_{1,2}+m_{2,1} \times m_{3,2}\right) \\
+\left(m_{3,1} \times m_{1,2}+m_{3,1} \times m_{2,2}\right)
\end{array}\right]^{-1} \\
= & {[1-0.1098]^{-1}=1.12402 }
\end{aligned}
$$$$
m_{\mathrm{n}, \mathrm{I}(\mathrm{i}+1)}=\mathrm{K}_{\mathrm{I}(\mathrm{i}+1)}\left[\begin{array}{l}
m_{\mathrm{n}, \mathrm{I}(\mathrm{i})} \times m_{\mathrm{n}, \mathrm{i}+1}+m_{\mathrm{H}, \mathrm{I}(\mathrm{i})} \\
\times m_{\mathrm{n}, \mathrm{i}+1}+m_{\mathrm{n}, \mathrm{I}(\mathrm{i})} \times m_{\mathrm{H}, \mathrm{i}+1}
\end{array}\right] \mathrm{n}=1 . . \mathrm{N}, \mathrm{i}=1
$$

Assume $\mathrm{I}(1)=1$

$$
\begin{aligned}
& \mathrm{m}_{1, \mathrm{I}(2)}=\mathrm{K}_{\mathrm{I}(2)}\left[\mathrm{m}_{1,1} \times \mathrm{m}_{1,2}+\mathrm{m}_{\mathrm{H}, 1} \times \mathrm{m}_{1,2}+\mathrm{m}_{1,1} \times \mathrm{m}_{\mathrm{H}, 2}\right]=0.1154 \\
& \tilde{\mathrm{m}}_{\mathrm{H}, \mathrm{I}(2)}=\mathrm{K}_{\mathrm{I}(2)}\left[\begin{array}{c}
\tilde{\mathrm{m}}_{\mathrm{H}, 1} \times \tilde{\mathrm{m}}_{\mathrm{H}, 2}+\tilde{\mathrm{m}}_{\mathrm{H}, 1} \\
\times \tilde{\mathrm{m}}_{\mathrm{H}, 2}+\tilde{\mathrm{m}}_{\mathrm{H}, 1} \times \tilde{\mathrm{m}}_{\mathrm{H}, 2}
\end{array}\right]=0.0138 \\
& \overline{\mathrm{m}}_{\mathrm{H}, \mathrm{I}(2)}=\mathrm{K}_{\mathrm{I}(2)}\left[\overline{\mathrm{m}}_{\mathrm{H}, 1} \times \overline{\mathrm{m}}_{\mathrm{H}, 2}\right]=0.2557 \\
& \mathrm{~m}_{\mathrm{H}, 1}=\overline{\mathrm{m}}_{\mathrm{H}, 1}+\mathrm{m}_{\mathrm{H}, 1}=0.2557 \\
& +0.0138=0.2695
\end{aligned}
$$

In the same way, assessment of the Statement1 property for the grade $H_{2}=$ average, $H_{3}=$ good are equal to 0.5401 and 0.0751 , respectively.

Step 4. By using equations $(11,12)$ and with the values calculated in step 3, we get the combined degrees of belief for the property Statement1 for different grade values.

$$
\begin{aligned}
& \beta_{1,1}=\frac{m_{1, I(L)}}{1-\overline{\mathrm{m}}_{H, I(L)}}=\frac{0.1154}{1-0.2557}=0.155 \\
& \beta_{2,1}=\frac{m_{2, I(L)}}{1-\overline{\mathrm{m}}_{H, I(L)}}=\frac{0.5401}{1-0.2557}=0.7257 \\
& \beta_{3,1}=\frac{m_{3, I(L)}}{1-\overline{\mathrm{m}}_{H, I(L)}}=\frac{0.0751}{1-0.2557}=0.1009 \\
& \beta_{H}=\frac{\widetilde{m}_{H, I(L)}}{1-\overline{\mathrm{m}}_{H, I(L)}}=\frac{0.0138}{1-0.2557}=0.0185
\end{aligned}
$$

Steps 1-4 can be employed for the other sub-trees with Statement2 at higher level, to obtain the combines degree of belief for that. Recursively Statement1 and Statement2 will be aggregated to form the combine degree of belief for general property at top level of hierarchy model. By applying the linear utility function as stated in step 5 in section 2.2, the score of the top level can be obtainable.

\section{Collecting evidence}

The ER procedure is a hierarchical evaluation of a complex property which is usually difficult to assess directly. In this case, to collect the necessary evidence to apply ER, maintenance-related wastes must first be identified. The hierarchical structure must then be developed based on the identified wastes. Finally, a qualitative survey can be constructed based on the criteria on the lowest level. The following sections go through each of these steps in turn.

\subsection{Identification of maintenance-related waste}

To identify maintenance-related waste in the automotive manufacturing industry, we held six workshops at five automotive manufacturing companies. Brainstorming was used as a main data collection tool. Thirty-six participants with an average of 14 years of experience in operational maintenance participated in the workshops. The participants' work tasks were spread over several positions: maintenance managers, maintenance line managers, maintenance supervisors, maintenance engineers and developers. The goal of the workshops, as presented 
to the participants also, was to identify as many maintenance-related wastes as possible within the automotive manufacturing industry. The workshops started by letting the participants brainstorm, on their own, for $10 \mathrm{~min}$. The participants were asked to write down their suggestions of maintenance-related waste on post-it notes. They then introduced their suggestions; gaining inspiration from the other participants, they were allowed to keep writing on their post-it notes, see Ahmadzadeh and Bengtsson [50]. At the end of the workshops, the post-it notes were gathered. A total of 465 post-it notes with suggestions on maintenance-related wastes were discussed during the workshops. We confirmed, even though it was not really asked for in the workshop topic, that the participants had focused on root causes of maintenancerelated wastes, not the symptoms of the wastes. For example, one participant wrote "poor machine maintainability," on one post-it note; this can be the root cause of many wastes, e.g., long time to diagnose failure, long time to repair, need for extra or special tools etc. Another participant wrote "incorrect or lacking autonomous maintenance;" this can be the root-cause of many wastes, e.g., machine disturbances, poor quality, unsafe conditions etc.

We took notes during the transcription of the post-it notes and while reading through the entire material began to categorize the wastes into larger categories. For instance, the postit note on poor machine maintainability went into the category "Waste created from poor Early Equipment Management (EEM)" and the note on incorrect or lacking autonomous maintenance was categorized as "Waste created in autonomous maintenance." The categorization into categories was performed by three researchers and through discussions, 16 final categories were decided upon; see Table 2 for all categories, see also Ahmadzadeh and Bengtsson [50, 51].

\subsection{Hierarchical structure for maintenance-related waste}

It was visible from the workshop analysis that the origin and cause of the maintenance-related wastes were linked to human factors. Therefore, in order for classification and model provision of maintenance-related waste linked to human activities, we consulted literature in the area of human factors in maintenance in a number of industries: aviation, mining, and nuclear power. A conceptual framework of human factors with wide acceptance across the government, military, and commercial sector is Reason's model [4]. Based on that, the most efficient and relevant classification system came from a study of maintainer error by the Naval Safety Center's Human Factors Analysis and Classification System-Maintenance Extension (HFACS$\mathrm{ME})$. The classification was adapted for maintenance mishaps in aviation [3]. It incorporates features of Heinrich's "Domino Theory" [52] and Edward's "SHEL Model" [53], as well as Reason's model, to depict factors that are precursors to accidents. These categories enable an analyst to identify failures at three levels, historically related to maintenance error: "management conditions," "maintainer conditions," and "working conditions." We therefore utilized the HFACS-ME as a basic framework and incorporated the 16 categories of maintenance-related waste found in the workshops into this model based on similarities.

The model was revised where no suitable category were found. In those cases, the categories were added to a subgroup among the main three categories. It was further revised by deleting some categories in HFACS-ME since some are more related to aviation, for instance, lighting/light and attention/ memory, etc. There is also some displacement in the revised model. For example, "maintainer acts," situated in an upper level in HFACS-ME, is now a subcategory of "maintainer condition," since "maintainer act" is influenced more by "maintainer condition." The revised model is called Maintenance-related Waste Classification based on Human Factors (MWC-HF) and is visualized in Table 3.

\subsection{Constructing survey based on criteria in the lowest level}

Based on the identified maintenance-related wastes, we next developed a survey on the lowest level of the hierarchy model. The survey contains 28 questions; it is assumed that all the waste attributes have equal relative weight (importance). Five distinctive evaluation grades are used to assess each question:

$\mathrm{H}=\left\{\begin{array}{l}\mathrm{H}_{1}=\text { Very low }, \mathrm{H}_{2}=\text { Low }, \\ \mathrm{H} 3=\text { Average, } \mathrm{H} 4=\text { High, } \mathrm{H} 5=\text { Very high }\end{array}\right\}$.

The respondents were asked to assess each waste by assigning their belief degree to these five grades. A belief degree represents the strength to which the grade is believed to be appropriate for describing the opinion on the criterion [29].

Note that an important advantage of ER is the possibility of handling uncertain information of any kind: lacking data, missing data, incomplete information. During the distribution of the survey, the respondent were told they could leave any question or any evaluation grade blank if they had no idea or were not sure.

For example subjective judgment of an expert for the first question about "how much "inadequate process" is responsible for waste was:

$$
\left(\begin{array}{l}
\text { Very low }=40 \%, \text { Low }=\text { "no idea", } \\
\text { Average }=20 \%, \text { High }=10 \%, \text { Very high }=0 \%
\end{array}\right) .
$$


Table 2 Categories of maintenance-related waste found in the workshop study

\begin{tabular}{llll}
\hline Items & Different categories of maintenance-related wastes & Number of wastes & SUM \% \\
\hline 1 & Waste created by human errors & 4 & 0.9 \\
2 & Waste created from poor planning & 45 & 9.7 \\
3 & Waste created in relation to knowledge/competence & 54 & 11.6 \\
4 & Waste created in general maintenance actions & 10 & 2.2 \\
4.1 & Waste created by preventive maintenance & 46 & 9.9 \\
4.2 & Waste created by corrective maintenance & 23 & 4.9 \\
4.3 & Waste created in autonomous maintenance & 17 & 3.7 \\
5 & Waste created from poor EEM (early equipment management) & 34 & 7.3 \\
6 & Waste created in poor spare part handling & 48 & 10.3 \\
7 & Waste created poor customer demand & 19 & 4.1 \\
8 & Waste created in relation to poor use of facts/data/system support & 41 & 8.8 \\
9 & Waste created in poor communication & 12 & 2.6 \\
10 & Waste created in poor organizational structures & 40 & 8.6 \\
11 & Waste created in purchase of external services & 10 & 2.2 \\
12 & Waste created in lack of employee engagement & 12 & 2.6 \\
13 & Waste created in recruitment & 4 & 0.9 \\
14 & Waste created from unstandardized processes & 32 & 6.9 \\
15 & Waste created in lack of prioritization & 10 & 2.2 \\
16 & Waste related to environment and safety & 4 & 0.9 \\
& SUM & 465 & 100.0 \\
\hline
\end{tabular}

In which some guidance about what kinds of activities are included to define "inadequate process." For example, "inadequate process" includes "Fail to enforce regulations," "Fail to provide oversight," "Fail to track performance," "Inadequate guidance," "Poor planning," etc. We collected 20 surveys from a group of employees with an average of 16-year experience in operational maintenance; the group consisted of repairmen and maintenance engineers and was employed at one of the companies that also participated in the workshops. Since the workshop study, which generated the empirics to develop the hierarchy model the survey is based upon, contained participants from maintenance managers, maintenance line managers, maintenance supervisors, maintenance engineers, and developers, it was opted that these should not be in the survey as well. Rather, we opted to go for repairmen and engineers to also see if there was a match between views from managerial positions and operative positions.

Group belief degree (GBD) for each evaluation grade was calculated based on Eq. (13):

$$
\begin{gathered}
H=\left\{\left(H_{i j}, \frac{1}{K} \sum_{k=1}^{K} \beta_{i j k}\right),\right. \\
i=1 \ldots 5, j=1 \ldots 28, K=20\}
\end{gathered}
$$

Where $K$ is equal to the number of maintenance experts, $i$ is the number of evaluation grades, and $j$ is the number of questions. For example for question number
1, the collected data (evidence) from 20 surveys are shown in the Table 4. By applying Eq. (13), the belief degree of 20 respondent were aggregated to form GBD for each evaluation grades to suit the ER framework. The column of GBD in Table 4 is equal to the first row in Table 5. The GBD for the rest of questions are shown in Table 5. In which, columns 2 to 6 show the percentage of grade values for each question across 20 respondents and the unassigned column shows the percentage of incomplete assessment, when group degree of belief is less than one.

Since ER, as mentioned in Section 2, is not easy to implement manually, we used Intelligent Decision System software [29].

\section{Data analysis and discussion}

We used the MWC-HF model as developed in the previous section to demonstrate how to apply the ER approach. The following calculations and Figs. 2-7 are generated using the user interfaces of the Intelligent Decision System (IDS) software and illustrated in the next sections. IDS is a general purpose multi-criteria decision support software developed on the basis of the evidential reasoning (ER) approach. IDS is different from most other MCDM software packages in that it can handle different types of uncertainties, such as randomness, ambiguity and ignorance in an integrated framework. It 
Table 3 Maintenance-related waste classification (MWC-HF) based on human factors

\begin{tabular}{|c|c|c|c|}
\hline First level & Second level & Third level & Fourth level \\
\hline \multirow[t]{29}{*}{ MWC-HF } & \multirow[t]{9}{*}{ Management condition } & \multirow[t]{5}{*}{ Organizational } & Inadequate process \\
\hline & & & Inadequate documentation \\
\hline & & & Inadequate design \\
\hline & & & Inadequate resources \\
\hline & & & Inadequate customer demand \\
\hline & & \multirow[t]{4}{*}{ Supervisory } & Inadequate supervision \\
\hline & & & Inappropriate operation \\
\hline & & & Uncorrected problem \\
\hline & & & Supervisory misconduct \\
\hline & \multirow[t]{13}{*}{ Maintainer condition } & \multirow[t]{3}{*}{ Medical } & Mental state \\
\hline & & & Physical state \\
\hline & & & Limitation \\
\hline & & \multirow[t]{4}{*}{ Crew condition } & Communication \\
\hline & & & Assertiveness \\
\hline & & & Adaptability/flexibility \\
\hline & & & Judgment/decision-making \\
\hline & & \multirow[t]{2}{*}{ Maintainer acts } & Error \\
\hline & & & Violation \\
\hline & & \multirow[t]{4}{*}{ Readiness } & Training preparation \\
\hline & & & Certification qualification \\
\hline & & & Lack of employee Engagement \\
\hline & & & Infringement \\
\hline & \multirow[t]{7}{*}{ Working condition } & \multirow[t]{2}{*}{ Environment } & Weather/indoor climate \\
\hline & & & Environmental hazards \\
\hline & & \multirow[t]{3}{*}{ Equipment } & Poor spare part handling \\
\hline & & & Poor EEM (early equipment management) \\
\hline & & & Unavailable/inappropriate \\
\hline & & \multirow[t]{2}{*}{ Workspace layout } & Confining \\
\hline & & & Inaccessible \\
\hline
\end{tabular}

uses belief decision matrices to preserve information structures in raw data and provides more informative outcomes. It provides support in problem structuring, data collection, group opinion aggregation and graphical presentation [29]. By using the IDS not only the process is technically supported but also cognitively supported.

\subsection{Distribution assessment}

We entered group belief degrees for each evaluation grades and for 28 questions (which were designed based on the lowest level of MWC-HF model) into IDS. Based on the ER approach, the distributed assessment on a higher level

Table 4 Belief degrees of 20 respondent for each evaluation grades and GBD for question 1

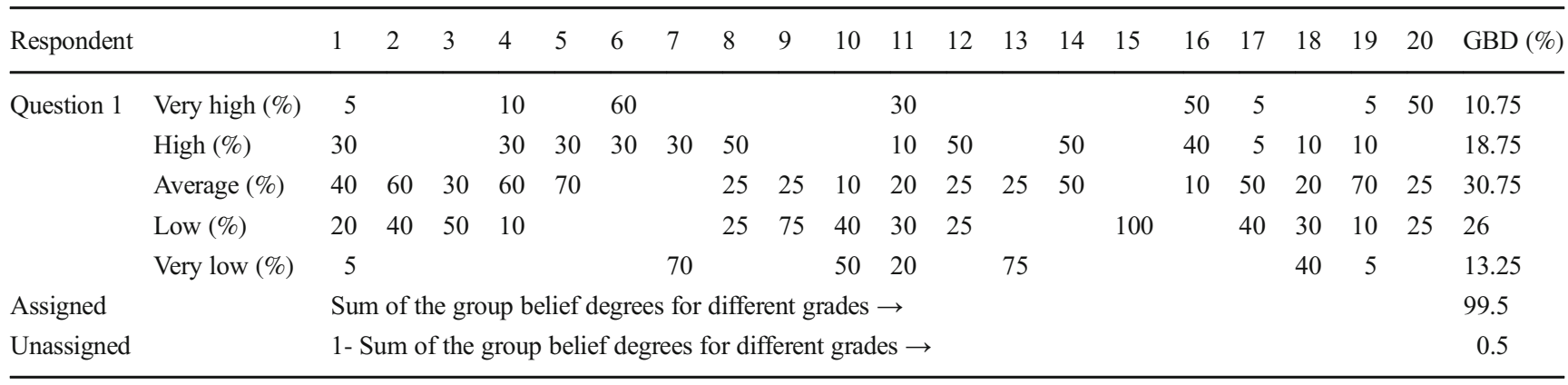


Table 5 Group belief degrees for each evaluation grade and for question in the survey

\begin{tabular}{|c|c|c|c|c|c|c|c|}
\hline Question & $\begin{array}{l}\text { Very high } \\
(\%)\end{array}$ & $\begin{array}{l}\text { High } \\
(\%)\end{array}$ & $\begin{array}{l}\text { Average } \\
(\%)\end{array}$ & $\begin{array}{l}\text { Low } \\
(\%)\end{array}$ & $\begin{array}{l}\text { Very low } \\
(\%)\end{array}$ & $\begin{array}{l}\text { Assigned } \\
(\%)\end{array}$ & $\begin{array}{l}\text { Unassigned } \\
(\%)\end{array}$ \\
\hline 1 & 10.75 & 18.75 & 30.75 & 26 & 13.25 & 99.5 & 0.5 \\
\hline 2 & 14 & 20.25 & 21.75 & 22 & 20.5 & 98.5 & 1.5 \\
\hline 3 & 12 & 20.5 & 19 & 20.75 & 27.25 & 99.5 & 0.5 \\
\hline 4 & 21 & 18.25 & 27.5 & 19 & 13 & 98.75 & 1.25 \\
\hline 5 & 5.75 & 15.75 & 14 & 22 & 41.25 & 98.75 & 1.25 \\
\hline 6 & 19.25 & 22 & 23.75 & 17 & 18 & 100 & 0 \\
\hline 7 & 6.5 & 20 & 29.5 & 18.75 & 23.25 & 98 & 2 \\
\hline 8 & 2.5 & 8.5 & 16.75 & 34.75 & 34.5 & 97 & 3 \\
\hline 9 & 7 & 9.5 & 11 & 34.25 & 37 & 98.75 & 1.25 \\
\hline 10 & 15.5 & 19.75 & 31.75 & 13 & 18 & 98 & 2 \\
\hline 11 & 6.25 & 14.25 & 18.25 & 34 & 26.75 & 99.5 & 0.5 \\
\hline 12 & 3.25 & 11 & 17.5 & 29.25 & 39 & 100 & 0 \\
\hline 13 & 13 & 12.25 & 13 & 26.25 & 33 & 97.5 & 2.5 \\
\hline 14 & 11 & 19.25 & 19.25 & 9.75 & 40.25 & 99.5 & 0.5 \\
\hline 15 & 15.25 & 23.75 & 12 & 14.75 & 34.25 & 100 & 0 \\
\hline 16 & 7.5 & 19.75 & 21.5 & 21.25 & 27.75 & 97.75 & 2.25 \\
\hline 17 & 3 & 5.25 & 15.25 & 31.3 & 44.2 & 99 & 1 \\
\hline 18 & 16 & 9.25 & 17.75 & 17.5 & 38.5 & 99 & 1 \\
\hline 19 & 12 & 8.75 & 5.75 & 14 & 49.5 & 90 & 10 \\
\hline 20 & 14.75 & 10.75 & 6.5 & 14 & 54 & 100 & 0 \\
\hline 21 & 5.25 & 2 & 5.75 & 39.25 & 31.9 & 84.15 & 15.85 \\
\hline 22 & 2.25 & 9.25 & 12.25 & 26 & 49.25 & 99 & 1 \\
\hline 23 & 9 & 8.5 & 9.05 & 23 & 49.95 & 99.5 & 0.5 \\
\hline 24 & 16 & 19 & 19.25 & 22.25 & 23.5 & 100 & 0 \\
\hline 25 & 20 & 15.5 & 19 & 15 & 24.75 & 94.25 & 5.75 \\
\hline 26 & 13.5 & 15.75 & 12 & 16 & 42.75 & 100 & 0 \\
\hline 27 & 2.5 & 5 & 19.25 & 19.05 & 46.7 & 92.5 & 7.5 \\
\hline 28 & 7.75 & 14 & 14 & 14.8 & 49.45 & 100 & 0 \\
\hline
\end{tabular}

criterion in the model is determined by its distributed assessment on the lower level criteria.

Therefore, in this part, the distributed assessment on different lower levels is calculated by IDS; see Table 6 and
Eqs. (14-17) for more clarity. An attribute hierarchy for lower level under "management condition" is shown in Fig. 2.

Following aggregation rules are used to calculate some part of the overall distribution assessment in Table 6.
Fig. 2 Attribute hierarchy of MWC-HF with detail for management condition by IDS

\section{MWC-HF}

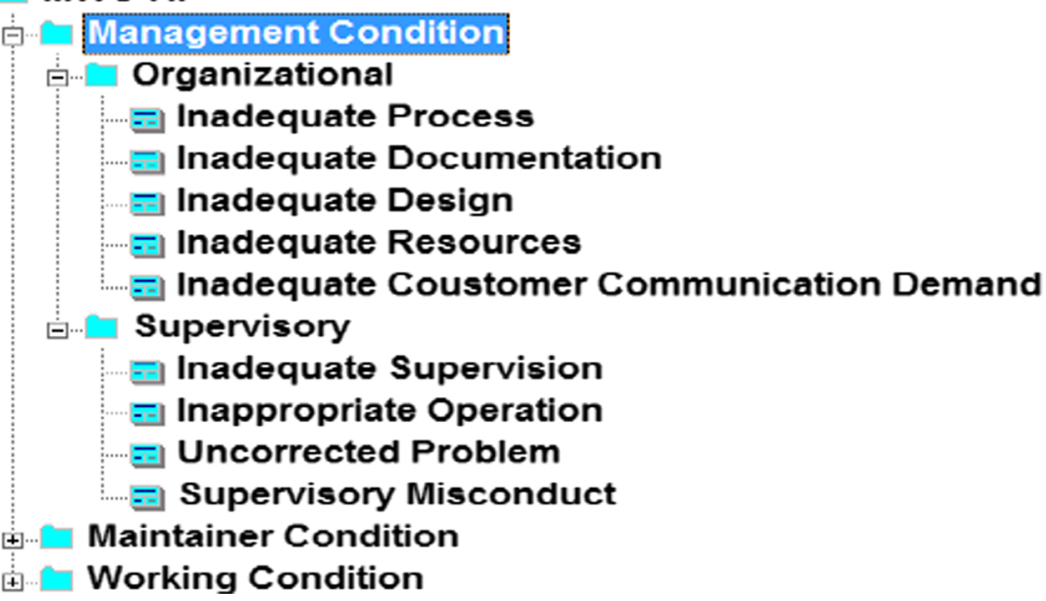


Fig. 3 Evaluation grades on second level attributes

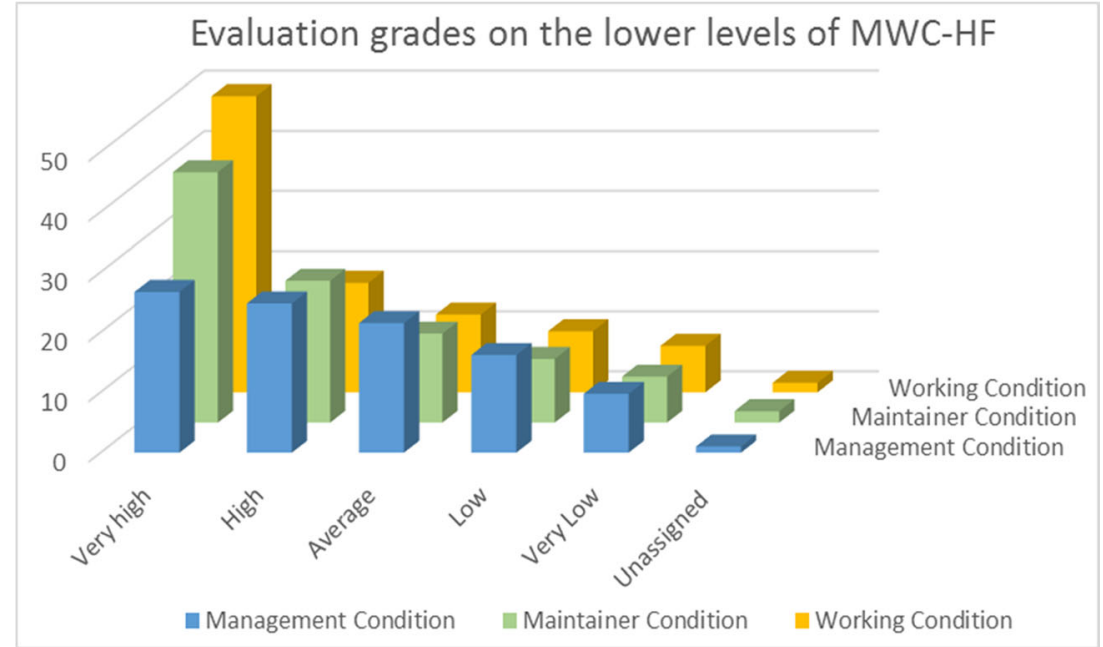

Organizational (3rd level) :

$=($ Inadequate Process $\oplus$ Inadequate Documentation $\oplus$ Inadequate Design $\oplus$ Inadequate Resources $\oplus$ Inadequate Customer Demand) $4^{\text {th }}$ level.

Supervisory (3rd level) :

$=($ Inadequate Supervision $\oplus$ Inappropriate Operation $\oplus$ Uncorrected Problem $\oplus$ Supervisory Misconduct) $4^{\text {th }}$ level.

Management Condition (2nd level) :

$=($ Organizational $\oplus$ Supervisory $) 3 r d$ level.

$M W C-H F(1$ st level) :

$=($ Management Condition $\oplus$ Maintainer Condition

$\oplus$ Working Condition) 2nd level.
In which symbol $\oplus$ shows the combination rules of ER approach for aggregation of distributed assessment. Table 6 shows the overall distributed assessment using MWC-HF with the lower level attributes. Figure 3 shows the distributed assessment with evaluation grades in the second level.

Figure 4 visualizes the overall distribution assessment for maintenance-related waste created by human factors; it provides a panoramic view of overall waste by aggregating the three areas: management condition, maintainer condition and working condition. It shows that the waste created by human factors in maintenance has the highest overall score in many areas; over $41 \%$ of the respondents graded it as "very high" and about $22 \%$ graded it as "high," creating a combined belief degree of over $64 \%$. In contrast, the lowest is graded at $7.73 \%$. The wastes
Fig. 4 Overall distribution assessment generated by IDS on MWC-HF

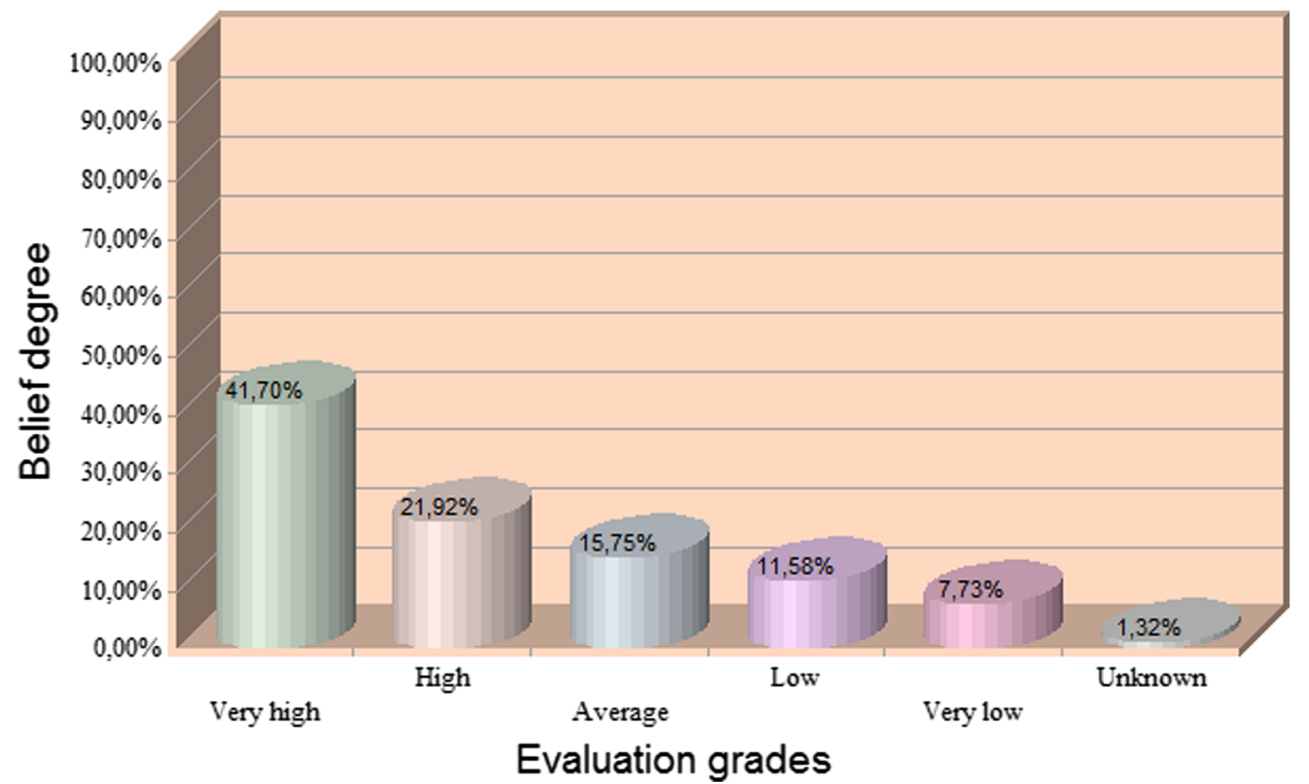


Fig. 5 Variation on average percentage score for the case company generated by IDS on MWC-HF

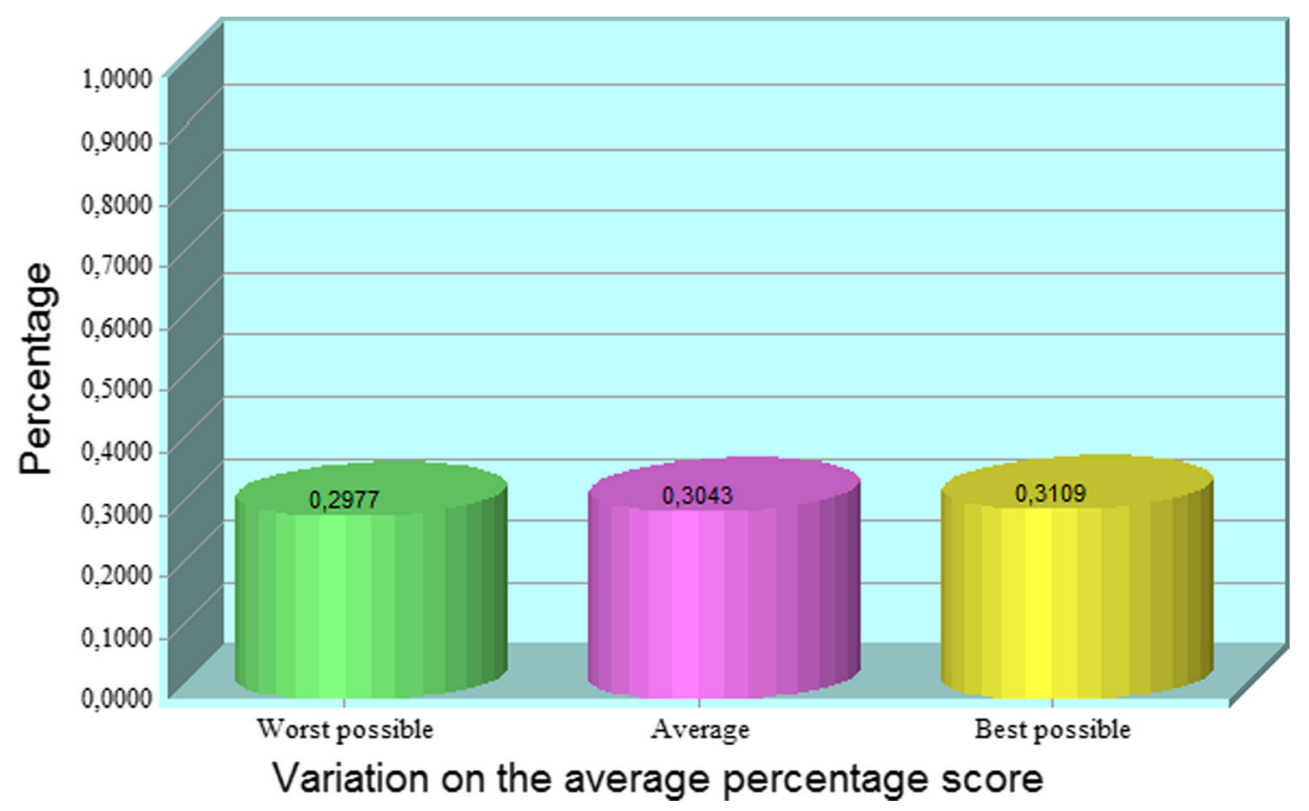

that the respondents were unable to identify were only $1 \%$, a good sign that most of maintenance-related waste created by human factors is recognized.

The combined assessment (CA) for the company can then be represented as follows:

$$
\begin{aligned}
\mathrm{CA}= & \{(\text { Very high }, 41.7 \%),(\text { High }, 21.9 \%) \\
& ,(\text { Average }, 15.7 \%),(\text { Low }, 11.6 \%),(\text { Very low }, 7.7 \%)\}
\end{aligned}
$$

On the whole, the average percentage score that the case company has achieved for maintenance-related waste by human factors based on 20 individual opinions is $43.58 \%$, with a variation between 43.13 and $44.03 \%$ calculated by IDS. The variation is caused by the unanswered questions; see Fig. 5. If several companies' maintenance-related waste were compared, this average percentage could be used as a reliable ranking method.
This assessment and comparison could be used in future research to see how factors in different companies are similar or different. It could also help determine whether researchers can create a single plan to reduce or eliminate waste or if every company needs a unique proposal.

\subsection{Prioritization of human factors in different levels}

Our main purpose in prioritization the human factors responsible for maintenance-related waste was to identify strengths and weaknesses which could form a basis for subsequent detailed assessments and help create action plan to address the weaknesses. To do so, we applied ER through IDS and got the average percentage score for the second level see Fig. 6. As result of IDS for rankings of maintenance-related waste at the second level shows, management condition to be in first place, with

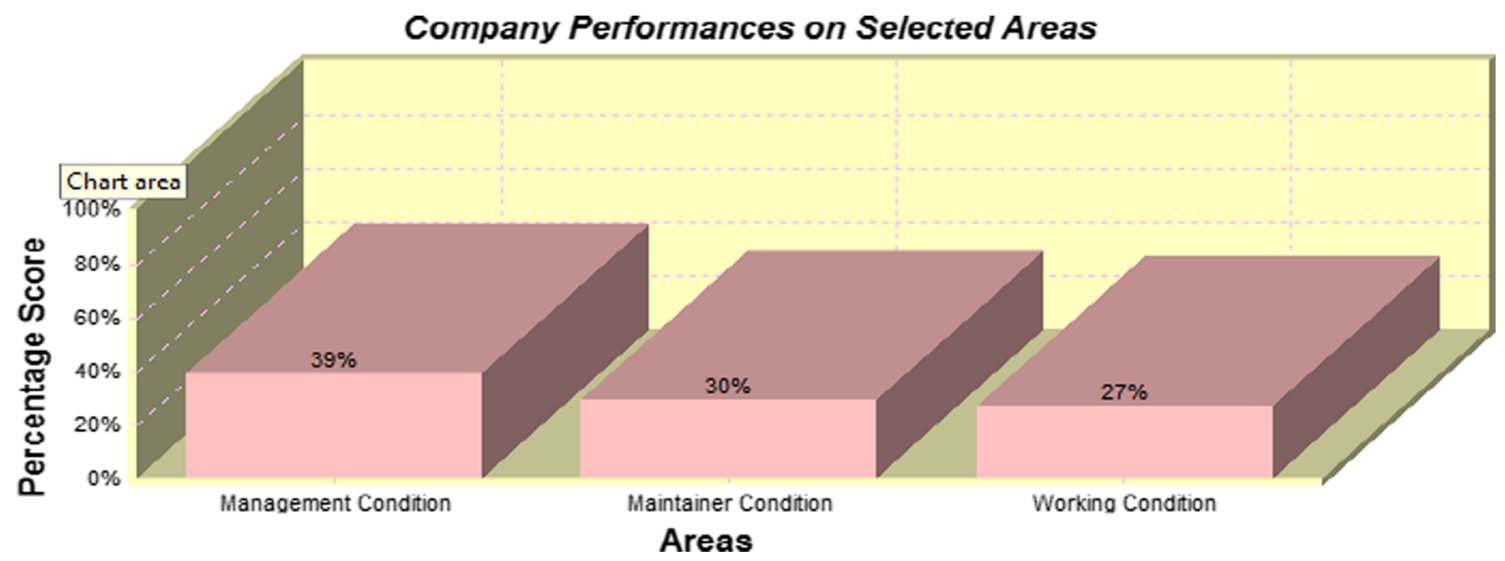

Fig. 6 Average percentage score of companies' maintenance waste on the second level 


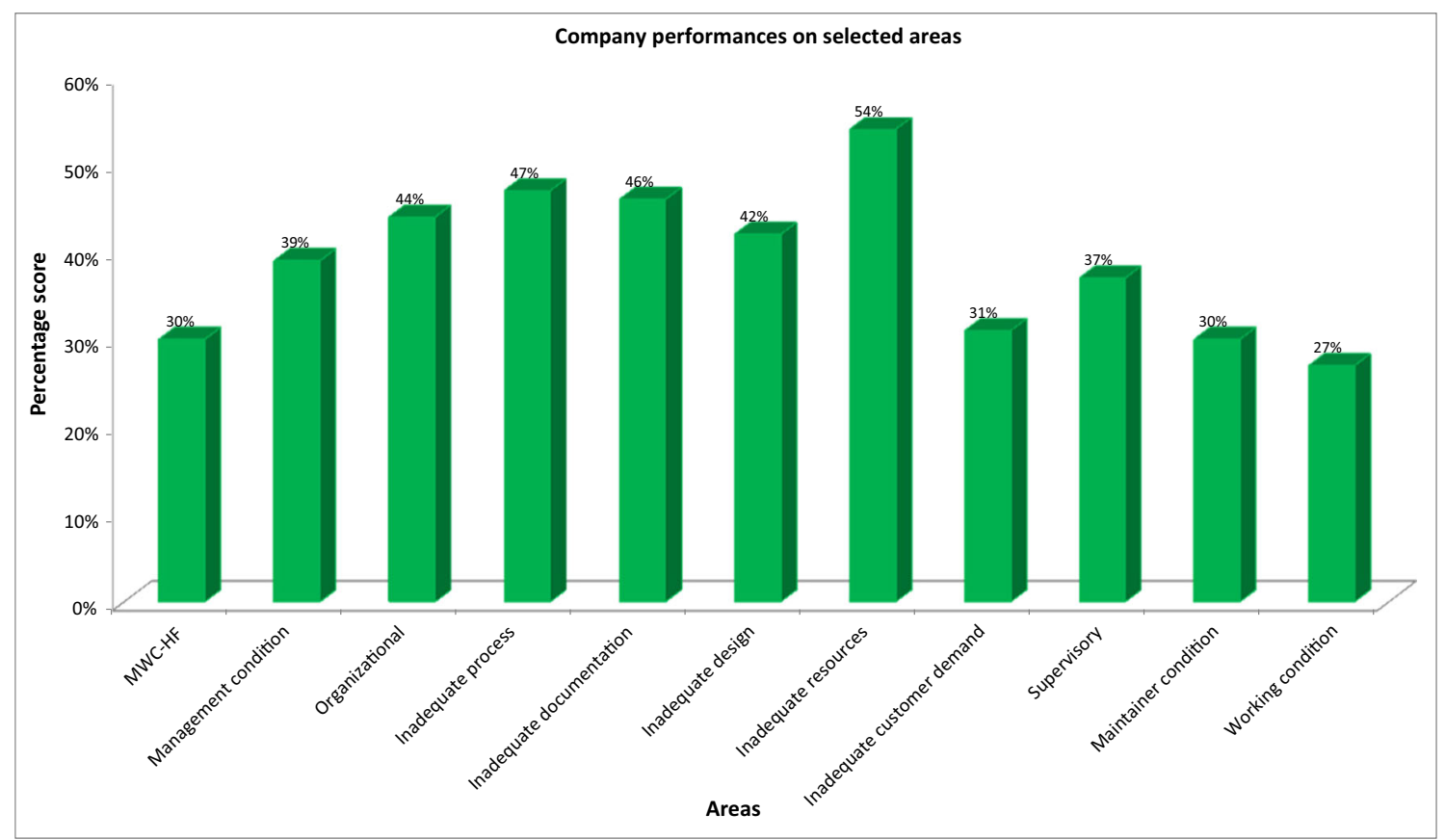

Fig. 7 Average percentage of maintenance-related waste at the organizational level

maintainer condition and working condition in second and third place respectively.

Given this information, the maintenance management team can focus on management condition to determine which factors are most important in the waste creation. On the management condition level, organizational factors have an average score of $44 \%$, putting them in first place. The supervisory factor comes second with average score of $37 \%$. Finally, on the third level, for organizational factors, IDS generates average scores of $54 \%$ for inadequate resources, $47 \%$ for inadequate processes, $46 \%$ for inadequate documentation, $42 \%$ for inadequate design, and $31 \%$ for inadequate customer communication demand; see Fig. 7. This means management teams can focus on different factors to reduce or eliminate waste based on their importance for creating waste; for instance, inadequate resources is the most important reason (highest score) for waste. Apart from upper level ranking scores, there are ranking scores for the third and fourth level of the attributes. This helps managers make action plans to reduce or

Table 6 Overall distributed assessment of MWC-HF on the lower level attributes

\begin{tabular}{|c|c|c|c|c|c|c|c|c|}
\hline \multirow{2}{*}{$\begin{array}{l}\text { General } \\
\text { attribute }\end{array}$} & \multirow[t]{2}{*}{ Basic attribute } & \multirow[t]{2}{*}{ Code } & \multicolumn{6}{|c|}{ Evaluation grade $(\%)$} \\
\hline & & & Very high & High & Average & Low & Very Low & Unassigned \\
\hline \multirow{12}{*}{$\begin{array}{l}\text { MWC-HF } \\
\quad(1 \text { st level })\end{array}$} & Organizational (3rd level ) & Org & 23.27 & 22.17 & 22.86 & 18.58 & 12.22 & 0.90 \\
\hline & Supervisory (3rd level ) & Sup & 29.05 & 26.71 & 20.08 & 14.51 & 8.25 & 1.39 \\
\hline & Management condition ( 2 nd level) & Man $=$ Org $\oplus$ Sup & 26.72 & 24.79 & 21.52 & 16.21 & 9.73 & 1.03 \\
\hline & Medical (3rd level ) & Med & 28.69 & 25.78 & 22.52 & 14.52 & 7.75 & 0.75 \\
\hline & Crew condition (3rd level ) & Crw & 35.79 & 17.56 & 15.96 & 18.43 & 11.10 & 1.17 \\
\hline & Maintainer acts (3rd level ) & Mai & 44.20 & 31.30 & 15.25 & 5.25 & 3 & 1 \\
\hline & Readiness & Rea & 47.31 & 20.39 & 8.26 & 7.09 & 11.28 & 5.67 \\
\hline & $\begin{array}{l}\text { Maintainer Condition } \\
\text { (2nd level) }\end{array}$ & Mai $=$ Med $\oplus$ Crw $\oplus$ Mai $\oplus$ Rea & 41.61 & 23.58 & 14.78 & 10.56 & 7.6 & 1.87 \\
\hline & Environment (3rd level ) & Env & 53.19 & 23.63 & 9.63 & 7.97 & 4.93 & 0.64 \\
\hline & Equipment (3rd level ) & Equ & 31.69 & 17.54 & 16.43 & 16.48 & 16.16 & 1.70 \\
\hline & Workplace Layout (3rd level ) & Wor & 51.88 & 15.94 & 15.61 & 8.76 & 4.65 & 3.16 \\
\hline & $\begin{array}{l}\text { Working condition } \\
\text { (2nd level) }\end{array}$ & Wor $=\mathrm{Env} \oplus \mathrm{Equ} \oplus$ Wor & 49.25 & 18.25 & 12.96 & 10.18 & 7.76 & 1.59 \\
\hline \multicolumn{3}{|c|}{$\begin{array}{l}\text { MWC-HF(1st level ) } \\
\quad=\text { Man } \oplus \text { Mai } \oplus \text { Wor }\end{array}$} & 41.70 & 21.92 & 15.75 & 11.58 & 7.73 & 1.32 \\
\hline
\end{tabular}


Table 7 Ranking of the third level of hierarchy model generated by IDS

\begin{tabular}{ll}
\hline Third level & Rank (\%) \\
\hline Equipment & 42 \\
Organizational & 39 \\
Crew condition & 38 \\
Supervisory & 37 \\
Medical & 37 \\
Readiness & 29 \\
Workspace layout & 25 \\
Maintainer acts & 23 \\
Environment & 22 \\
\hline
\end{tabular}

eliminate the factors creating waste. For example, in the third level, "equipment" has an average score of $42 \%$, while "environment" has $22 \%$, making them the highest and lowest scores in the third level, with other factors situated between them; see Table 7. In the fourth level, "inadequate resources" and "weather

Table 8 Ranking of the fourth level of hierarchy model generated by IDS

\begin{tabular}{ll}
\hline Fourth level & Rank $(\%)$ \\
\hline Inadequate resources & 54 \\
Inadequate supervision & 52 \\
Mental state & 50 \\
Poor EEM (early equipment management) & 48 \\
Inadequate process & 47 \\
Inadequate documentation & 46 \\
Poor spare part handling & 45 \\
Adaptability/flexibility & 43 \\
Inadequate design & 42 \\
Inappropriate operation & 42 \\
Judgment/decision-making & 40 \\
Assertiveness & 38 \\
Communication & 37 \\
Training preparation & 37 \\
Physical state & 35 \\
Unavailable/inappropriate & 35 \\
Inadequate customer demand & 31 \\
Certification qualification & 27 \\
Lack of employee engagement & 30 \\
Inaccessible & 30 \\
Supervisory misconduct & 29 \\
Limitation & 27 \\
Infringement & 29 \\
Uncorrected problem & 24 \\
Environmental hazards & 23 \\
Confining & 29 \\
Error and violation & \\
Weather/indoor climate & 29 \\
\hline & 29 \\
\hline
\end{tabular}

/indoor climate," with average scores of 54 and $22 \%$, respectively, are the highest and lowest average scores for creating maintenance-related waste; other factors are situated between them; see Table 8.

\section{Conclusion}

The paper has identified and ranked maintenance-related waste caused by human factors. A total of 465 types of maintenancerelated waste were discussed in the workshops. These were assigned to 16 categories created after analysis. Subsequent analysis showed that the origin of maintenance-related waste can be linked to human factors. We therefore consulted literature in the area of human factors in maintenance.

A conceptual framework by Reason [4] with wide acceptance in different sectors and industries was accepted as the basic framework. The 16 workshop categories were incorporated into the hierarchy model of HFACS-ME based on similarities. Finally, 28 questions were developed based on the lowest level of the hierarchy model with the assumption that all wastes have equal relative weight (importance). The respondents were asked to evaluate each waste by assigning a degree of belief to each question. Then, ER was applied using IDS software to rank the identified factors. Results showed that, on an overall level, management condition, maintainer condition, and working condition are in first, second, and third place respectively as most responsible in creating maintenance-related waste by human factors. On the most delimited level, "inadequate resources" and "weather/indoor climate" have the highest and lowest average scores, respectively, by ER in ranking. This prioritization methodology can be used as a tool to create awareness for managers seeking to reduce or eliminate maintenance-related waste caused by human factors. Future research should apply this assessment methodology in different companies to determine if the creation of waste is similar or different. It should consider whether researchers can create a general plan to reduce or eliminate waste or if every company needs its own proposal.

Acknowledgments This research work has been funded by VINNOVA through the "FFI - Hållbar produktionsteknik" research programme, and Mälardalen University. The research work is also a part of the initiative for Excellence in Production Research (XPRES) which is a cooperation between Mälardalen University, the Royal Institute of Technology, and Swerea. XPRES is one of two governmentally funded Swedish strategic initiatives for research excellence within Production Engineering. The authors would like to thank Prof. Dong-Ling Xu advices, comments and review which helped to improve the quality of the article and access to open source IDS work package for their valuable contribution to embedded computing.

Open Access This article is distributed under the terms of the Creative Commons Attribution 4.0 International License (http:// creativecommons.org/licenses/by/4.0/), which permits unrestricted use, distribution, and reproduction in any medium, provided you give appropriate credit to the original author(s) and the source, provide a link to the Creative Commons license, and indicate if changes were made. 


\section{References}

1. Wireman T (1990) World class maintenance management. Industrial Press, Inc., New York

2. Dahlgaard JJ, Dahlgaard-Park SM (2006) Lean production, six sigma quality, TQM and company culture. TQM Mag 18(3):263-281

3. Schmidt, J., Lawson, D., Figlock, R. (2003) Human factors analysis and classification system maintenance extension (HFACS-Me), review of select NTSB maintenance mishaps, an update. http://www.faa.gov/about/initiatives/maintenance hf/library/documents/media/hfacs/ntsb_hfacs-me_updated_ study report.pdf

4. Reason, J. (2000). Cognitive engineering perspective on maintenance errors. Cognitive engineering in the aviation domain. Lawrence Erlbaum Associates

5. Dhillon BS, Liu Y (2006) Human error in maintenance: a review. J Qual Maint Eng 12(1):21-36

6. Ohno T (1988) Toyota production system, beyond large-scale production. CRC Press, Cambridge

7. Davis, C., Greenough, R.M. (2010) Measuring the effectiveness of lean thinking activities within maintenance. http://plantmaintenance-resourcecenter.com/articles/Lean_Maintenance.pdf.

8. Bicheno J, Holmweg M, Anhede P, Hillberg J (2011) Ny verktygslåda för lean - filosofi, transformation, metoder och verktyg. Revere, Göteborg

9. Baluch N, Abdullah CS, Mohtar S (2012) TPM and lean maintenance: a critical review. Interdisciplinary. Journal of Contemporary Research in Business 4(2):850-857

10. Gaonkar, R.S.P., Min, X., Verma, A.K., Rui P. (2010) Using evidential reasoning approach for ship turbine's condition monitoring techniques ranking. Conference on Industrial Engineering and Engineering Management (IEEM), pp 2398-2402

11. Belton V, Stewart TJ (2002) Multiple criteria decision analysis: an integrated approach. Kluwer, Dordrecht

12. Jacquet-Lagreze E, Siskos J (1982) Assessing a set of additive utility functions for multi-criteria decision making: the UTA method. European Journal of Operation Research 10:151-164

13. Lekurwale RR, Akarte MM, Raut DN (2015) Framework to evaluate manufacturing capability using analytical hierarchy process. Int J Adv Manuf Technol 76(1):565-576

14. Paramasivam V, Senthil V, Rajam Ramasamy N (2011) Decision making in equipment selection: an integrated approach with digraph and matrix approach, AHP and ANP. Int J Adv Manuf Technol 54(9):1233-1244

15. Saaty, T.L. (1988) The analytic hierarchy process. University of Pittsburgh

16. Bandara N, Gunaratne M (2001) Current and future pavement maintenance prioritization based on rapid visual condition evaluation. J Transp Eng 127(2):116-123

17. Chen CT (2001) A fuzzy approach to select the location of the distribution center. Fuzzy Sets Syst 118:65-73

18. Chen, M.F., Tzeng, G.H., Ding, C.G. (2003) Fuzzy MCDM approach select service provider. IEEE Conference on Fuzzy Systems. Los Alamitos

19. Hodgett RE (2015) Comparison of multi-criteria decision-making methods for equipment selection. Int J Adv Manuf Technol:1-13

20. Kumar Mehlawat M, Gupta P (2016) A new fuzzy group multicriteria decision making method with an application to the critical path selection. Int J Adv Manuf Technol 83(5):1281-1296

21. Liao R, Zheng H, Grzybowski S, Yang L, Zhang Y, Liao Y (2011) An integrated decision-making model for condition assessment of power transformers using fuzzy approach and evidential reasoning. IEEE Transactions on Systems, Man and Cybernetics 26(2):1111-1118
22. Prakash, T.N. (2003). Land suitability analysis for agricultural crops: a fuzzy multicriteria decision making approach. Master of Science thesis. Enschede, Netherlands

23. Sandra AK, Vinayaka Rao VR, Raju KS, Sarkar AK (2007) Prioritization of pavement stretches using fuzzy MCDM approach: a case study. Soft Computing in Industrial Applications 39:265-278

24. Sanja P, Radivoj P (2002) A new fuzzy multi-criteria methodology for ranking alternatives. Int Trans Oper Res 9:73-84

25. Shafer GA (1976) Mathematical theory of evidence. Princeton University Press, Princeton

26. Zhang, Z.J., Yang, J.B., Xu, D.L. (1990) A hierarchical analysis model for multi-objective decision making. Analysis, Design and Evaluation of Man-Machine System. Oxford, UK, pp 13-18

27. Yang JB, Singh MG (1994) An evidential reasoning approach for multiple attribute decision making with uncertainty. IEEE Transactions on Systems, Man, and Cybernetics 24(1):1-18

28. Yang JB, Xu DL (2002a) On the evidential reasoning algorithm for multi-attribute decision analysis under uncertainty. IEEE Transactions on Systems, Man and Cybernetics Part A Systems and Humans 32(3):289-304

29. Xu DL, Yang JB (2008) Application of an intelligent decision system to nuclear waste repository option analysis. International Journal of Nuclear Governance, Economy and Ecology 2(2):146-165

30. Xu DL (2012) An introduction and survey of the evidential reasoning approach for multiple criteria decision analysis. Annual Operation Research 195(1):163-187

31. Guo M, Yang JB, Chin KS (2009) Evidential reasoning approach for multi-attribute decision analysis under both fuzzy and interval uncertainty. IEEE Trans Fuzzy Syst 17(3):683-697

32. Huynh VN, Nakamori Y, Ho TB, Murai T (2006) Multiple attribute decision making under uncertainty: the evidential reasoning approach revisited. IEEE Transactions on Systems, Man and Cybernetics 36(4):804-822

33. Xu DL, Yang JB, Wang YM (2006) The evidential reasoning approach for multi-attribute decision analysis under interval uncertainty. European Journal of Operation Research 174(3):1914-1943

34. Yang JB (2001) Rule and utility based evidential reasoning approach for multi-attribute decision analysis under uncertainties. European Journal of Operation Research 131(1):31-61

35. Yang ZL, Mastralis L, Bonsall S (2009) Incorporating uncertainty and multiple criteria in vessel selection. Journal of Engineering for the Maritime, Environment 223:177-188

36. Sen P, Yang JB (1995) Multiple criteria decision making in design selection and synthesis. J Eng Des 6(3):207-230

37. Wang J, Yang JB (2001) A subjective safety based decision making approach for evaluation of safety requirements specifications in software development. International Journal of Reliability Quality and Safety Engineering 8(1):35-57

38. Yang JB, Dale BG, Siow CHR (2001) Self-assessment of excellence: an application of the evidential reasoning approach. Int $\mathrm{J}$ Prod Res 39(16):3789-3812

39. Gao, L., Mock, T.J., Srivastava, R.P. (2011) An evidential reasoning approach to fraud risk assessment under Dempster-Shafer theory: a general framework. Conference on System Sciences. Hawaii. USA

40. Rahgan S, Mirzazadeh A (2012) A new method in the location problem using fuzzy evidential reasoning. Research Journal of Applied Science, Engineering and Technology 4(22):4636-4645

41. Tang, S.Q., Xu, D.L. (2015) Plant location selection under uncertainty: a case study of an American family owned manufacturing company in Asia. Conference on Multiple Criteria Decision Making (MCDM15). Hamburg. Germany

42. Browne, F., David, B., Weiru, L., Yan, J., Colm, H., Niall, R., Hui, W. (2012) Application of evidence theory and discounting techniques to aerospace design. Conference on Information Processing and Management of Uncertainty in Knowledge-based Systems, Catania, Italy 
43. Neumann T, Adam W (2012) Expert systems based on DempsterShafer theory of evidence in maritime: characteristic and applications. Scientific Journals Maritime, University of Szczecin 32(104): 141-147

44. Yang, J.B., Xu, D.L., Chen, Y-W (2015) Consumer preference prediction to support New Product Development (NPD). Conference on Multiple Criteria Decision Making (MCDM15). Hamburg. Germany

45. Yang, Y., Chen, Y.W., Xu. D.L. (2015) A belief rule based expert system for predicting consumer preference in new product development. Conference on Multiple Criteria Decision Making (MCDM15). Hamburg. Germany

46. Massahi, M., Mirzazadeh, A., Mirzadeh, P.A (2012) The evidential reasoning approach for supplier's prioritization with group-AHP weights. Conference on Industrial Engineering and Operations Management, Istanbul, Turkey, 1945-1953

47. Wang JQ, Nie RR, Zhang HY, Chen XH (2013) Intuitionistic fuzzy multi-criteria decision-making method based on evidential reasoning. Appl Soft Comput 13(4):1823-1831
48. Xu, D. L., Foster, C., Hu, Y., Yang, J. B. (2014) Decision support system for evaluating impact of product carbon labeling scheme. Frontiers of Engineering Management, 89-104

49. Pontus, J., Nordström, L., Lagerström, R. (2007) Formalizing analysis of enterprise architecture. Enterprise Interoperability, pp 35-44

50. Ahmadzadeh, F., Bengtsson, M (2015a) Prioritization of maintenance related waste using evidential reasoning approach. Conference on Multiple Criteria Decision Making (MCDM15). Hamburg. Germany

51. Ahmadzadeh, F., Bengtsson, M (2015b) Classification of maintenance-related waste based on human factors. Conference on Operations, Management for Sustainable Competitiveness (22nd EurOMA). Neuchatel. Switzerland

52. Heinrich HW, Petersen D, Roos N (1980) Industrial accident prevention: a safety management approach. McGraw-Hill, New York

53. Hawkins FH (1993) In: Orlady HW (ed) Human factors in flight, 2nd edn. Ashgate, Aldershot 